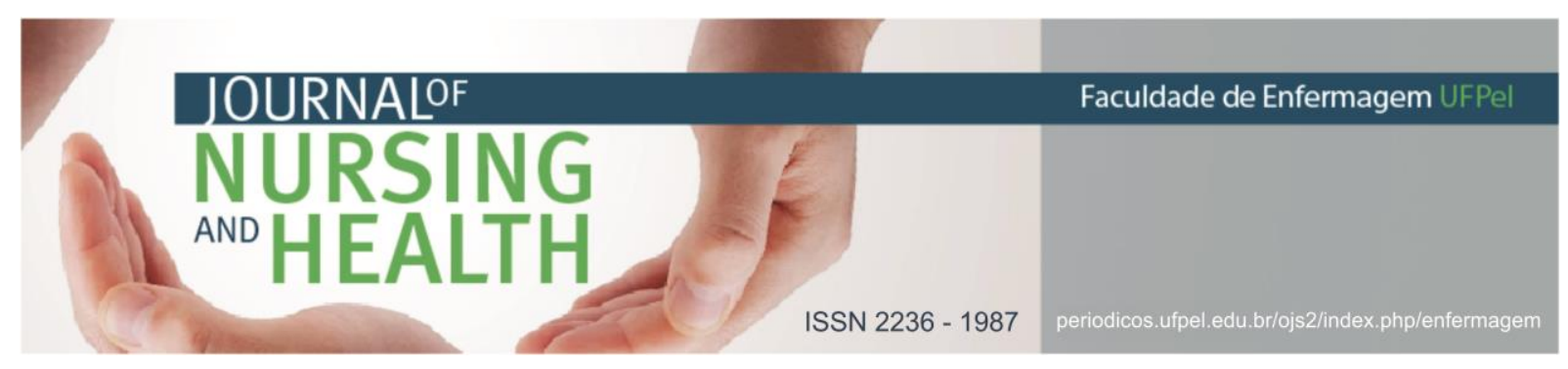

ARTIGO ORIGINAL

\title{
Educação permanente no processo de trabalho em saúde mental
}

\author{
Permanent education in the work process in mental health
}

Educación permanente en el proceso de trabajo en salud mental

Pinheiro, Maria Carolina da Costaㄹ ; Hypólito, Álvaro Luiz Moreira²; Kantorski, Luciane Prado³

Como citar este artigo: Pinheiro MCC, Hypólito ALM, Kantorski LP. Educação permanente no processo de trabalho em saúde mental. J. nurs. health. 2019;9(2):e199203

\section{RESUMO}

Objetivo: reafirmar o potencial da Educação Permanente como constitutiva e qualificadora do processo de trabalho em saúde mental. Métodos: trata-se de um recorte da Pesquisa de Avaliação dos Centros de Atenção Psicossocial da Região Sul do Brasil, através de observações de campo, entrevistas semiestruturadas com profissionais, e análise hermenêutica e dialética. Resultados: organizadas nas categorias diversidade de atores, horizontalidade das relações e problematização/resolutividade, evidenciaram-se ações de Educação Permanente em Saúde como atividades de educação em saúde, de planejamento, avaliação das práticas e resolução dos problemas. Considerações Finais: ações de Educação Permanente em Saúde são potencialmente constitutivas e qualificadoras do processo de trabalho em saúde, e precisam ser valorizadas e incorporadas ao cotidiano dos serviços de saúde mental, como um modo de resistência ao enfrentamento dos desafios do Sistema Único de Saúde.

Descritores: Educação continuada; Saúde mental; Pesquisa qualitativa

\section{ABSTRACT}

Objective: to reaffirm the potential of the Permanent Education as constitutive and qualifying of the work process in mental health. Methods: this is a clipping from the Evaluation Research of the Psychosocial Care Centers of the Southern Region of Brazil, through field observations, semistructured interviews with professionals, and hermeneutic-dialectical analysis. Results: organized in the following categories: diversity of actors, horizontality of relationships and problemsolving/resolving, Permanent Education actions in Health were evidenced as activities of health education, planning, evaluation of practices and resolution of problems. Final Considerations: Permanent Health Education actions are potentially constitutive and qualifiers of the health work process and need to be valued and incorporated into the daily life of mental health services, as a way of resisting the challenges of the Unified Health System.

Descriptors: Education, continuing; Mental health; Qualitative research

\footnotetext{
1 Enfermeira. Doutora em Ciências. Secretaria Estadual da Saúde do Estado do Rio Grande do Sul (SES/RS). Email: carolinapmeirelles@yahoo.com.br http://orcid.org/0000-0003-1567-2347

2 Pedagogo. Doutor em Curriculum and Instruction. Universidade Federal de Pelotas (UFPEL). E-mail: alvaro.hypolito@gmail.com http://orcid.org/0000-0003-1487-0413

${ }^{3}$ Enfermeira. Doutora em Enfermagem. Universidade Federal de Pelotas (UFPEL). E-mail: kantorski@uol.com.br http://orcid.org/0000-0001-9726-3162
} 


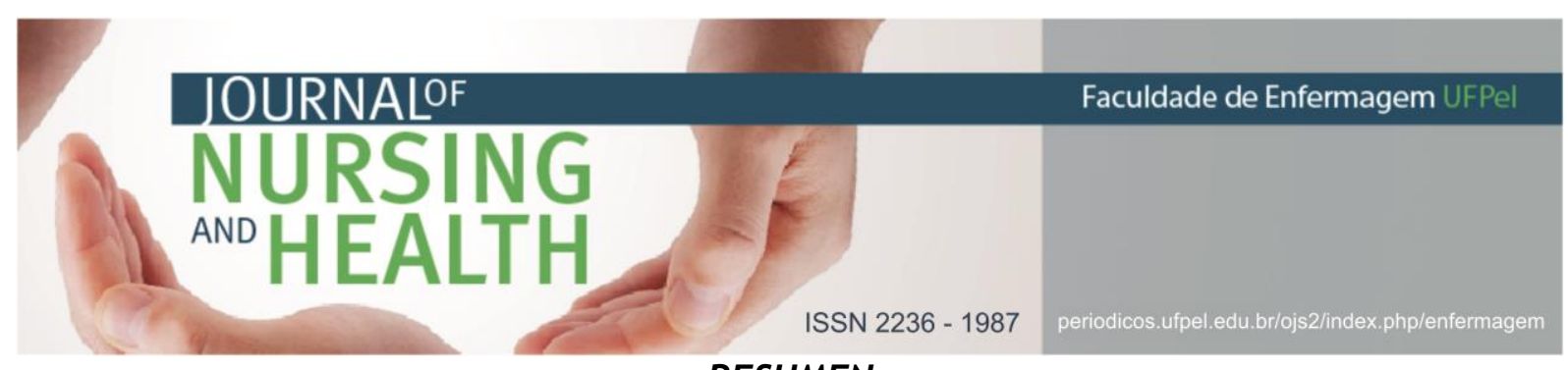

RESUMEN

Objetivo: reafirmar el potencial de la Educación Permanente como constitutiva y calificadora del proceso de trabajo en salud mental. Métodos: recorte de la Investigación de Evaluación de los Centros de Atención Psicosocial de la Región Sur de Brasil, por observaciones de campo y entrevistas semiestructuradas con profesionales, y análisis Hermenéutica-dialéctica. Resultados: organizadas en las categorías diversidad de actores, horizontalidad de las relaciones y problematización/resolutividad y las evidencias de las acciones de Educación Permanente en Salud fueran las actividades de educación en salud, planificación, evaluación de las prácticas y resolución de los problemas. Consideraciones Finales: acciones de Educación Permanente en Salud son potencialmente constitutivas y calificadoras del proceso de trabajo en salud, y necesitan ser valoradas e incorporadas al cotidiano de los servicios de salud mental, como una resistencia al enfrentamiento de los desafíos del Sistema Único de Salud.

Descriptores: Educación continua; Salud mental; Investigación cualitativa.

\section{INTRODUÇÃO}

Entre os desafios não superados para consolidação do Sistema Único de Saúde (SUS), apontam-se os insuficientes avanços no que dizem respeito às relações entre Gestão do Trabalho e Educação em Saúde. Primeiramente pela inexistência de um Plano de Carreira, Cargos e Salários para o SUS, e pela ampliação da precarização do trabalho resultante das reformas trabalhistas e de alterações nas políticas de saúde como da atenção básica e da saúde mental, as quais têm contribuído com possibilidades de constituição de equipes e desenvolvimento de ações e serviços que reforçam a fragmentação do trabalho em saúde.

Neste cenário, em que o trabalho em saúde se encontra cada vez mais fragilizado, é preocupante o discurso sobre uma gestão inovadora, dando centralidade à questão da Educação Permanente em Saúde (EPS) não como Educação Permanente (EP), mas de gerenciamento permanente, no qual ao contrário de um instrumento de transformação radical, converte-se em uma ideologia que seduz apenas por sua aparência de novidade pedagógica. ${ }^{1}$

Ainda que, a constituição de equipes multiprofissionais continue sendo preconizada por políticas e programas de saúde, percebe-se ênfase nas especialidades e no modelo biomédico centrado em práticas individuais, dificultando o trabalho interdisciplinar e a produção coletiva de saberes e fazeres.

Os trabalhadores buscam respostas para suas questões cotidianas, e para tal demandam por um espaço terapêutico de discussão e adequado ao acolhimento de suas angústias e inquietações. ${ }^{2}$

Trabalhadores de saúde carecem de reflexão e reorganização dos seus processos de trabalho para enfrentarem as prementes dificuldades da produção em saúde que cuide das necessidades do indivíduo e das coletividades.

Desde a implantação da Política Nacional de Educação Permanente em Saúde (PNEPS) em 2004, foram criadas relevantes ações como o Programa Nacional de Reorientação da Formação 


\section{JOURNALOF \\ NURSING \\ ANO HEALTH}

ISSN 2236 - 1987

programa ou um curso que oferte algum saber já constituído, e que ao ser transmitido possa resolver todos os seus problemas na produção do cuidado em saúde.

A transformação de práticas e mudanças no modo de cuidar, a partir da formação e do desenvolvimento dos profissionais da área de saúde é condição para consolidação do SUS, e que exigem mudanças no modo de ensinar e de aprender.

A EPS propõe ações facilitadoras aos processos de trabalho, fundamentais na mudança de modelos de atenção à saúde, mas precisa ser compreendida para além da formulação da política e de programas e sim na sua essência, como uma tecnologia que o trabalhador pode dispor e utilizar no processo de trabalho, muitas vezes sem a devida valorização e ressignificação.

No Brasil, apesar de certo avanço conceitual sobre a EPS, pela utilização da concepção problematizadora como aporte para as ações educativas, ainda são necessários além do comprometimento de gestores e trabalhadores, a compreensão e aplicação da EPS, com investimentos capazes de transformarem a realidade do cotidiano dos serviços de saúde, que efetivamente contribuam com a redução das ações desarticuladas dos processos de trabalho. ${ }^{5}$

Mesmo reconhecida como uma ferramenta de gestão importante a ser gradativamente incorporada ao trabalho dos profissionais, e sendo contemplada nas diretrizes, objetivos, metas e financiamento dos planos de saúde, a EPS tem seus esforços mais 


\section{JOURNALOF \\ NURSING \\ AND HEALTH}

ISSN 2236 - 1987

efetivos ao aproximarem-se dos locais de trabalho e ao apoiarem a interpretação, problematização e intervenção nas concretas situações de saúde. ${ }^{6}$

A EPS é um dispositivo potente para qualificar a gestão e o trabalho em saúde, quando se propõe a construir um SUS pautado pela necessidade, de mudar o modo de cuidar e o processo de governar na saúde. Antes de uma opção restrita ao técnico-administrativo, a gestão em saúde precisa ser concebida como processo pedagógico e inventivo; consiste em modos de estar nos serviços, de se relacionar, de se conectar e de se constituir em alteridade. $^{7}$

Trata-se de uma estratégia que deve ser incorporada ao cotidiano da gestão e do cuidado, como ferramenta para tomada de decisão e condução dos serviços de saúde, considerando o papel educativo como inerente a qualquer indivíduo. Transformar toda ação em aprendizagem e conhecimento é fonte de transformação do processo de trabalho, na qual as pessoas que vivenciam juntas uma experiência na atenção, gestão, formação ou controle social em saúde, podem enfrentar os problemas

pedagogicamente as práticas concretas. $^{8}$

$\mathrm{Na}$ área de saúde mental os desafios da Luta Antimanicomial e os constantes ataques a Reforma Psiquiátrica também exigem maiores esforços em EPS para que de fato seja possível manter a defesa dos direitos das pessoas com sofrimento psíquico, tendo como princípios o direito à inclusão social, à cidadania e à atenção integral à saúde em liberdade, longe dos manicômios e das práticas asilares. Para tanto, é necessário problematizar as práticas vigentes e construir novos modos de cuidar a partir da experiência cotidiana que se transforma em aprendizagem.

Esses desafios fazem parte dos processos de formação na perspectiva da atenção psicossocial e da desinstitucionalização, afetando diretamente os serviços municipais de saúde mental, que somente no período de 2001 a 2010 tiveram o ingresso de cerca de trinta mil novos profissionais, que junto aos existentes necessitam de estratégias de supervisão e educação permanente. ${ }^{9-10}$

Entre as estratégias de EPS voltadas para as necessidades específicas da área de saúde mental estão os esforços produzidos pela reorientação de programas de residência médica e multiprofissional, Escolas de Supervisores ClínicoInterinstitucionais, Escolas de Redução de Danos do SUS, o PET Saúde Mental, o Curso "Caminhos do Cuidado" e em destaque o Programa de Percursos Formativos, como proposta de fortalecimento das práticas do cuidado na perspectiva da atenção psicossocial. ${ }^{9}$

Os Centros de Atenção Psicossocial (CAPS), ainda como serviços estratégicos para reforma psiquiátrica envolvem mudanças no processo de trabalho, principalmente para garantir no cotidiano, um cuidado que se afaste de qualquer semelhança com o modelo manicomial, e que seja alicerçado no acolhimento, estímulo à 


\section{JOURNALOF \\ NURSING \\ AND HEALTH}

ISSN 2236 - 1987

As entrevistas foram gravadas e as observações foram registradas em diários de campo. A análise realizada teve como base a Hermenêutica e Dialética, contemplado o contexto histórico, a descrição do serviço, o perfil dos trabalhadores e as ações de EPS. Os resultados foram sistematizados em três categorias, conforme as características mais relevantes: diversidade de atores; horizontalidade das relações; problematização/resolutividade. ${ }^{13}$

Todos entrevistados concordaram em participar da pesquisa mediante assinatura de consentimento livre e esclarecido, em todas as suas etapas. 0 anonimato dos participantes foi garantido pela identificação da letra $\mathrm{E}$ para entrevista e 0 para observação, seguidas do número do respectivo entrevistado ou observador. Os profissionais estão identificados pela formação ou atividade realizada no CAPS, e usuários citados têm nomes fictícios.

\section{RESULTADOS E DISCUSSÃO}

As atividades reconhecidas por diversas características como ações de EPS no processo de trabalho de um CAPS carregam em si o potencial de uma prática pedagógica.

Estas atividades podem fortalecer a concretização da integração ensinoserviço, como prevê a política de EPS e facilitam aos trabalhadores 0 entendimento de que é no próprio cotidiano do trabalho que podem ser identificadas as respostas para resolução de seus problemas, a partir da construção dos conhecimentos necessários. Para sistematização dos resultados, definiram-se três princípios 
básicos de EPS, como categorias analíticas que possam identificar uma ação ou atividade de trabalho como uma prática de Educação Permanente em Saúde, apresentados na Figura 1:

Figura 1: Princípios Básicos de EPS

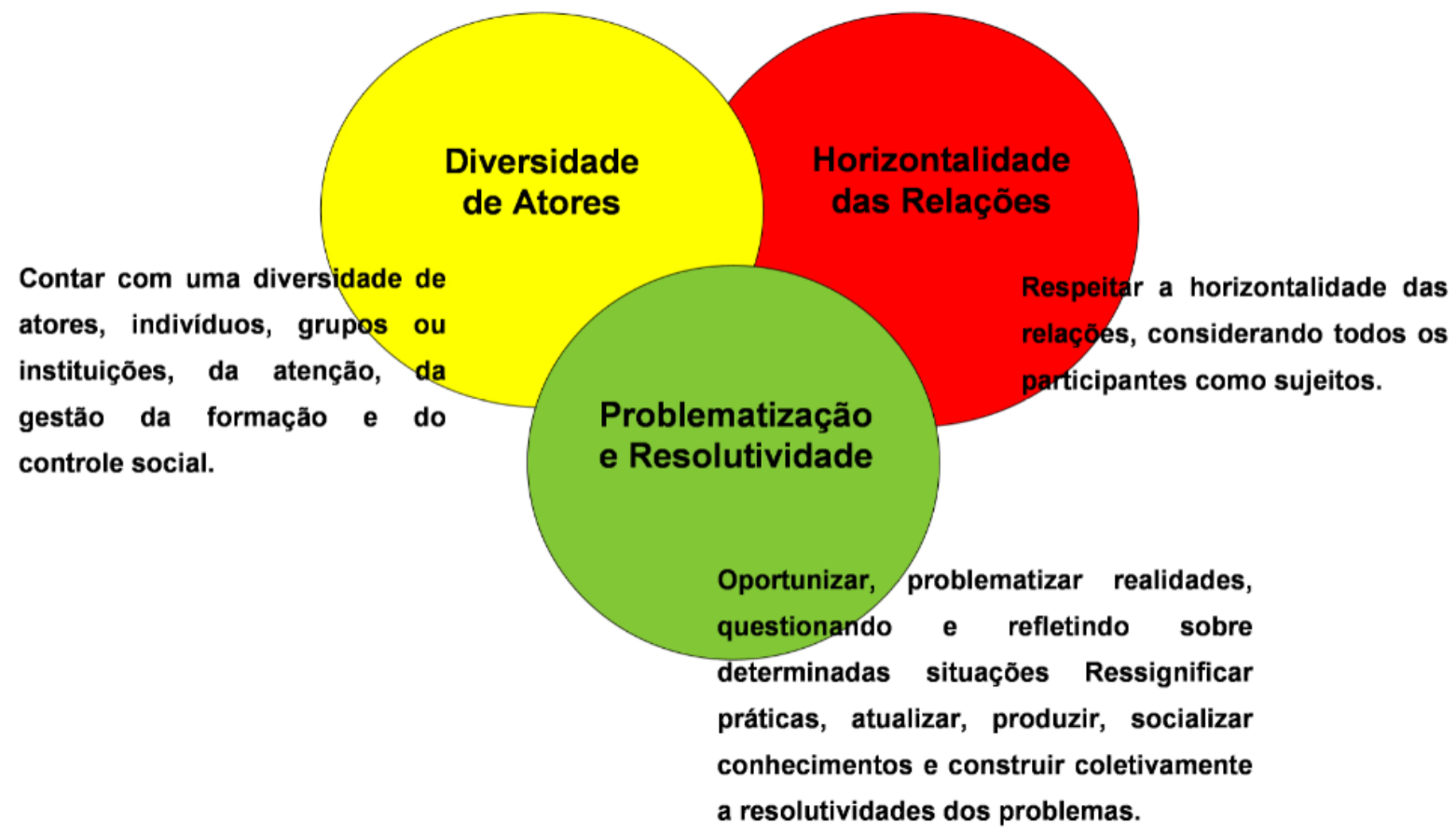

Fonte: produção dos autores, 2009.

$\mathrm{Na}$ apresentação destes princípios não se tem a pretensão de reduzir ou simplificar conceitualmente a EPS, mas apontar uma diretriz que facilite um caminho para possível compreensão e análise de ações de Educação Permanente.

As características consideradas relevantes em cada categoria ou princípio são aspectos observados no desenvolvimento das atividades do CAPS, que apontam e justificam o reconhecimento de ações de EPS, conforme as referências e discussões apresentadas, sendo todas de extrema importância. Neste artigo, apresentaremos os resultados e discussões com ênfase na Problematização e Resolutividade.

Esta temática apresenta características que reúnem uma série de atividades que oportunizam problematizar realidades, questionando e refletindo sobre determinadas situações, que são capazes de ressignificar práticas, atualizar, produzir e socializar conhecimentos, bem como construir coletivamente a resolutividade dos problemas.

Para enfrentarem os desafios do trabalho em saúde no contexto da Reforma Psiquiátrica, as equipes precisam aprofundar e aperfeiçoar estratégias que permitam qualificar o 


\section{JOURNALOF

processo de trabalho primando pela resolutividade dos serviços, através da descentralização e democratização do poder, bem como criação de processos de educação permanente. ${ }^{14}$

Nos resultados apresentados neste artigo, procura-se destacar as atividades de educação em saúde, planejamento, avaliação das práticas e resolução de problemas, desenvolvidas no cotidiano do serviço objeto do estudo.

Em relação à Educação em saúde, discutimos algumas atividades desenvolvidas com os usuários e outras voltadas aos trabalhadores. Para começar, entende-se como parte das ações de EPS que caminham para problematização e resolutividade de problemas a valorização do interesse dos atores e utilização de informações do cotidiano, relacionadas ao contexto e a cultura, como se pode observar nas oficinas de alfabetização.

[...] trabalhamos com aquele potencial que todos nós temos e que todos eles têm que todos nós somos capazes. (E17)

[...] o que eu trago para eles é o dia de hoje, é o que eles estão assistindo na televisão, o quê que foi que mais chamou a atenção deles ontem à noite e o quê que foi hoje. (E24)

[...] a professora propõe que os usuários pesquisem três palavras que comecem com as letras $L, P$, $Q$ R. [...] Cada um diz quais as palavras que encontraram, e a oficineira convida a todos para fazerem um cartão convidando para a festa de aniversário do serviço amanhã. (01)

Percebe-se nestes discursos uma aproximação com a abordagem problematizadora de Paulo Freire, de uma educação crítica e dialógica, que busca o objeto de aprendizagem na cultura do educando e na consciência social e política que ele tenha da mesma, devolvendo o conhecimento de forma organizada e sistematizada, transformando-o num sujeito social de uma práxis libertadora. ${ }^{15}$

Educação e Saúde como temas inseparáveis e que se integram nas mais diferentes ações.

Então, eles sabem que eles podem produzir alguma coisa. Porque eu nunca coloco assim, que eu ensino alguma coisa, de maneira nenhuma, nós estamos aprendendo todos juntos. (E17)

A professora passava lições na lousa, e os alunos conforme iam terminando perguntavam se suas lições estavam corretas. (03)

Observa-se, que o profissional de saúde assume seu papel pedagógico, coloca-se como um professorfacilitador que ensina, aprende e avalia. Aspectos que se reforçam com a oficina de alfabetização que sem dúvida é uma atividade pedagógica, mas que tem outro sentido quando realizada em um serviço de saúde, no qual o profissional da educação se transforma em profissional de saúde, e o usuário é um aluno-educando, que também é avaliado e explicita seus resultados de aprendizagem.

Compreendendo-se que entre um sujeito e um objeto de aprendizagem 


\section{JOURNALOF \\ NURSING \\ ANO HEALTH \\ ISSN 2236 - 1987}

existe uma situação de aprendizagem, é preciso valorizar as diferentes formas de assimilação e apreensão do conhecimento, de modo que na prática do ensino, deve-se compreender mais as formas de como se aprende do que como se ensina. ${ }^{16}$

Uma das usuárias pegou uma espécie de cartilha e lia alto, um tanto rápido, "encrencava" em algumas palavras, mas lia muito bem [...]. Em seguida ela passou uma "continha" na lousa. Ela explicou que os livros, escrita e desenho, trazem aprendizado de leitura e de números também, como contas, [...]. (03)

A experiência desta atividade nos aponta a potência de uma ação cotidiana da oficina de alfabetização do CAPS, como promotora de autonomia e de construção de um sujeito social a partir de diferentes modos de ensinar e aprender.

Educação e saúde também andam juntas, quando as mesmas atividades que promovem o cuidado, ensinam e promovem autonomia. A satisfação de usuários de CAPS, ${ }^{17}$ entre outros está relacionado ao seu posicionamento, em que nas oficinas, aprendem atividades, e passam a ser proativos ensinando atividades aos demais, como se pode observar no discurso:

[...] então aquela pessoa fazia o corte de cabelo, a unha. Essas coisas básicas assim, então essa pessoa mostrava para eles como é bom, tudo isso, por questão da autoestima. [...] tem coisas que, na verdade a gente resolve toda a vida dele, bem como tu viu ontem, desde ir ali comprar TV [televisor], ensinar, fazer com que eles aprendam comprar, com que eles aprendam a administrar a sua casa, o seu dinheiro. (E1)

Estas evidências reforçam a possibilidade da aprendizagem no trabalho, em que o aprender e o ensinar se incorporam ao quotidiano das organizações e ao próprio processo de trabalho.

Em atividades voltadas aos trabalhadores, acredita-se ter evidenciado umas das mais relevantes ações de EPS, principalmente por se entender que estas foram definitivas em influenciar o desenvolvimento do processo de trabalho deste serviço, que sem dúvida demonstra preocupação com a EP de todos os profissionais da rede, não pelas atividades em si, mas pelo modo como foram desenvolvidas.

[...] trabalhávamos com um mecanismo que era da educação permanente, que era o ciclo regional de saúde mental coletiva [...] tivemos várias pessoas cursando especialização em saúde mental coletiva. (E5)

A incorporação de conhecimentos aprendidos no processo de trabalho da equipe em atividades cotidianas se transforma também em metodologias ativas de aprendizagem, valorizando vivências e rodas de conversa com trocas de experiências.

[...] a gente está fazendo um trabalho no hospital com os enfermeiros e técnicos de enfermagem que trabalham no posto psiquiátrico, [...] lá, toda a terça a gente fazia uma conversa 


\section{JOURNALOF \\ NURSING \\ AND HEALTH}

com o pessoal, para ouvir o que eles tão sentindo, porque trabalhar neste local [...] nós trouxemos eles para passar um dia com a gente, cada um. Até para eles saberem que essa pessoa que está lá, como é a vida dela aqui dentro. Aí eles viram nosso trabalho, viram como que é o funcionamento. (E1)

[...] os policiais têm um tratamento diferenciado com os pacientes, a equipe fez uma capacitação com eles neste sentido, e os pacientes em geral, tendem a se acalmar com tal abordagem. (03)

A atualização permanente dos trabalhadores torna-se cada vez mais complexa, à medida que os conhecimentos e saberes tecnológicos se renovam de forma cada vez mais rápida na área da saúde, e pode-se pensar na flexibilidade que o CAPS propõe para que os profissionais interajam e construam suas práticas, por meio da soma dos saberes, da interação e da consciência de que existem conhecimentos que são tão necessários ou mais, do que saber técnico. ${ }^{18}$

[...] as rodas do saber, da psicóloga que fez o ano passado [...] nós sempre tínhamos aquela coisa: quem vai para um curso, quem vai para um encontro, traz como de volta? Com alguns, a gente conseguia repartir, com outros não. Ela fez um projeto, que era de poder a gente fazer encontros que fossem de educação e de capacitação. Então, ao mesmo tempo em que tu vais, tu vens e faz a devolução, montando a aula ou exposições, ou painéis. Outro dia a psicóloga trabalhou o tema da desinstitucionalização, e assim vai. $E$ tem momentos que o pessoal trouxe um usuário para falar, trouxe familiar, e cada um coloca a sua visão e a gente faz o debate. [...] é uma forma de estar sempre trabalhando os conceitos de acordo com a reforma psiquiátrica, com a questão de inserção social, da cidadania. Eu acho que isso é o que mantém a questão da educação permanente. (E5)

Estudos sobre EP em saúde mental demonstram que momentos de diálogo construídos relacionalmente, numa perspectiva interacional de espaço-como são fundamentais, sejam através de cursos, seminários, reuniões de equipe, fóruns, ou no próprio cotidiano dos serviços, a partir da articulação de histórias, desejos, práticas e saberes. ${ }^{19-20}$

A possibilidade de reconfiguração do processo de trabalho está na educação em saúde desenvolvida de forma dialógica e horizontalizada, numa situação em que os sujeitos participam ativamente da ação educativa. ${ }^{21}$

\section{Atividades de planejamento de} ações também foram significativamente observadas, principalmente nas reuniões de equipe, como espaço organizado e privilegiado, dando conta do que não é possível de ser problematizado, ressignificado e melhor planejado no dia a dia do serviço. 


\section{ISSN $2236-1987$}

Planejamento como uma ação sobre a organização das práticas de saúde tornando-as coerentes com a finalidade da ação institucional e contribuindo para as políticas públicas neste âmbito. ${ }^{7}$

A gente tem a nossa reunião de planejamento, no início do ano, então $a$ gente faz o planejamento, e no final do ano a gente tem a nossa reunião de avaliação, sempre [...]. (E1)

[...] e às vezes o tumulto do dia a dia não deixa a gente se comunicar. Então na reunião de terça a gente faz toda uma relação, fulana não está usando medicação, fulana se queixou de tal coisa, e leva isso para reunião, que certamente na reunião a psicóloga dela, a assistente social, o pessoal vai estar lá. Fica todo mundo a par do que acontece. (E2)

As reuniões de equipe são esperadas como o momento do processo de trabalho do serviço em que podem resgatar suas experiências cotidianas e as compartilhar com todos da equipe, mas acima de tudo ressignificá-las, possibilitando 0 planejamento das ações, como instrumento legítimo e indispensável para um trabalho com qualidade.

A valorização das reuniões pela própria equipe se entende como um qualificador do processo de trabalho e potencial desencadeador de uma ação de EPS, e que também se observa como espaço de atividade de avaliação das práticas.
A avaliação em saúde é indispensável para que durante os processos em curso, permita corrigir ou evitar erros, estabelecendo estratégias que possam qualificar o serviço prestado.

[...] a gente nunca pensa que a gente está pronta e que a gente sabe tudo. [...] a gente está sempre reavaliando a nossa prática. (E4)

Nem sempre dá certo, as coisas, se não dá certo voltamos para reunião de equipe "o que é que nós vamos fazer?” [...]. (E12)

Os discursos mostram que em geral as preocupações dos profissionais em avaliar suas práticas se concentram em questões de estrutura e processo, não sendo evidentes avaliações de resultado, o que também ainda se faz necessário, assim como, a definição de instrumentos e indicadores que qualifiquem o processo avaliativo. Contudo, observou-se que ocorrem de forma participativa e responsiva, de modo que o avaliador se coloca também como objeto da avaliação.

Profissionais percebem a EPS como instrumento de trabalho que possibilita reflexão e problematização das práticas, especialmente em reuniões de planejamento das ações, ainda que apontem dificuldades na operacionalização como limites no tempo e pouco incentivo de gestores. ${ }^{22}$

Além de planejar e avaliar, a resolução de problemas, como a expressão dos resultados das atividades de planejamento e avaliação, mesmo que provisoriamente é compreendida como àquela capaz de 


\section{JOURNALOF \\ NURSING \\ AND HEALTH}

ISSN 2236 - 1987

responder às necessidades de uma determinada situação.

As reuniões de equipe, como uma atividade coletiva possibilitam que os profissionais tragam suas vivências, discutam conceitos, contextualizem os nós críticos das diversas situações de acordo com sua realidade. Isso torna a reunião de equipe um modo de aprendizagem significativa, constituindo-a em espaço de educação permanente, vital na prática profissional nos serviços de saúde.

As reuniões de equipe, assim como outras atividades cotidianas dos serviços de saúde mental são apontadas por profissionais de saúde, como modos de fazer e como espaços de EPS capazes de promoverem conexões entre diferentes trabalhadores e práticas, reforçados pelo diálogo e articulação de saberes e fazeres. ${ }^{18}$

Na discussão de casos, também se identifica uma atividade que, sem dúvida, permite informar, socializar, ensinar e aprender, planejar, avaliar e resolver problemas.

[...] a gente discute bastantes casos, coisas que às vezes a gente não consegue no dia a dia, então, a gente leva para reunião da equipe e consegue resolver [...]. (E7)

A resolução de problemas advém de expor e questionar situações que, ao serem colocadas na roda, oportunizam a construção de encaminhamentos, de movimentos que não negam a existência das dificuldades, mas que se dispõem a ação e a práticas que resultem em alguma intervenção na realidade vivenciada pelos atores.

Em experiência de EPS num CAPS, foi observado que mesmo em momentos críticos carregados de sentimentos de paralisação, as conversas ainda que parecendo saturadas pelos problemas, também se constituem em momentos generativos, construídos pelas relações e pelo diálogo. ${ }^{20}$

Resolução de problemas não é o fim de uma situação, em que todos os questionamentos se esgotam em consensos. É necessário ressignificar os conflitos, levantar novas questões e manter o processo educativo de transformação da realidade permanentemente.

\section{CONSIDERAÇÕES FINAIS}

A EPS, tanto do ponto de vista conceitual como de política pública, tem a sua intencionalidade, mas não se pode considerá-la como algo prescritivo. Sua função é estimular os profissionais de saúde a se corresponsabilizarem pelo modelo de atenção, como resultado de suas práticas cotidianas do processo de trabalho, e reconhecê-lo como espaço privilegiado e legítimo para construção de novos conhecimentos e novas práticas.

O processo de trabalho produz conhecimento quando promove autonomia e faz dos atores sujeitos do seu próprio cuidado, de modo singular, ao ensinar a ler e escrever, a fazer compras, a tomar a medicação, a fazer capoeira, ou nas mobilizações comunitárias; e constrói saberes e fazeres a partir do trabalho de uma 


\section{ISSN $2236-1987$}

equipe, que socializa e troca conhecimentos nas rodas do saber ou nas reuniões que discutem casos, planejam, avaliam práticas e resolvem problemas.

A ação educativa em saúde, na perspectiva da EPS, é transformadora de todos os atores envolvidos em sujeitos responsáveis, pela produção da sua própria saúde e da coletividade. Atribuir o valor ou o significado de educação a uma ação em saúde pressupõe elevá-la a possibilidade de uma relação coletiva, em que o ensinar e o aprender pode levar à emancipação, à liberdade ou à autonomia de quem participa.

Atividades de um CAPS compreendidas como pedagógicas são potencialmente ações de EPS. Contudo este estudo não permite concluir que em todos os casos isto seja naturalmente possível, pois o que determina sua relação com a EPS é o modo como são operadas, ou seja, as suas potencialidades de serem transformadoras. Bem como, é relevante o contexto histórico do local estudado, e o perfil dos participantes, que demonstram um conjunto de características de envolvimento e de empoderamento, com ações técnicas e políticas de implicação com a construção da saúde local.

É preciso transformar o modelo de atenção à saúde que na maioria das vezes ainda é serviço-centrado, em um modelo voltado para o indivíduo e para coletividade de sujeitos que necessitam de ações no território, para além da estrutura física dos serviços. Um modelo que inclua todos os espaços em que as pessoas participem, trabalhem, estudem, sofrem, amem, vivem e produzem saúde.

Espera-se que as ações de EPS apresentadas neste estudo, deem visibilidade ao protagonismo das ações realizadas cotidianamente, junto aos serviços de saúde mental, e que apontem a utilização da EPS como princípio, instrumento e prática capaz de ressignificar e redimensionar os processos de trabalho.

Considera-se ter sido possível reafirmar o potencial da Educação Permanente como constitutiva e qualificadora do processo de trabalho em saúde, contribuindo em especial com os CAPS, ao apontar características que valorizem as atividades de EPS, como tecnologias de trabalho extremamente eficazes na qualificação da atenção à saúde prestada, e que podem ser desenvolvidas no cotidiano dos diversos serviços de mental, como um modo de resistência ao enfrentamento dos atuais desafios do Sistema Único de Saúde.

Por fim, tem-se a consciência que ainda é necessário levantar muitas outras questões que possibilitem novos e mais complexos estudos a respeito de processos de trabalho e das possibilidades de protagonismo da Educação Permanente em Saúde.

\section{REFERÊNCIAS}

1 Lemos CLS. Educação Permanente no Brasil: educação ou gerenciamento permanente? Ciênc. Saúde Colet. [Internet]. 2016[acesso em 2018 nov 22];21(3):913-22. Disponível em http://scielo.br/pdf:/csc/v21n3/1413 -8123-csc21-03-0913.pdf 
2 Medeiros GT, Nascimento FAF, Pavón RG, Silveira FA. Educação Permanente em Saúde Mental. Interface comun. saúde educ. [Internet]. 2016[acesso em 2019 mar 18];20(57):475-83. Disponível em: http://scielo.br/pdf/icse/v20n57/180 7-5762-icse-1807-576220150232.pdf

3 Omura JBB, Kuhnen M, Arruda MP, Locks GA. Educação permanente na estratégia de saúde da família: desafios dos processos formativos em saúde. Comunicações [Internet]. 2015[acesso em 2019 mar 19];22(1):211-26. Disponível em: https://www.metodista.br/revistas/r evistas-

unimep/index.php/comunicacoes/arti cle/view/2122

4 Ministério da Saúde (BR). Secretaria da gestão do Trabalho e da Educação na Saúde. Programa para o Fortalecimento das Práticas de Educação Permanente em Saúde no SUS: manual técnico 2018 [Internet]. Brasília; 2018[acesso em 2019 abr 19]. Disponível em: http: / / metodista.br/revistas/revistasunimep/index.php/comunicacoes/arti cle/view/2122f/2018/marco/28/Manu al-Tecnico-PRO-EPS-SUS-MINUTA1710.pdf.

5 Campos KFC, Sena RR, Silva KL. Educação Permanente nos Serviços de Saúde. Esc. Anna Nery Rev. Enferm. [Internet]. 2017[acesso 2018 nov 22];21(4)1-10. Disponível em: http://www.scielo.br/pdf/ean/v21n4 /pt_1414-8145-ean-2177-9465-EAN2016-0317.pdf

6 Vendruscolo C, Delazere JC, Zocche DAA, Kloh A. Educação permanente como potencializadora da gestão do sistema de saúde brasileiro: percepção dos gestores. Rev. enferm. UFSM. [Internet]. 2016[acesso em 2018 nov 22];6(1):143-53. Disponível em: https://periodicos.ufsm. br/reufsm/ar ticle/view/20229/pdf

7 Capra MLP. A Educação Permanente em Saúde como dispositivo de gestão setorial e de produção de trabalho vivo em saúde. [tese] [Internet]. Porto Alegre (RS): Universidade Federal do Rio Grande do Sul; 2011[acesso em 2019 abr 19]. Disponível em: https: / / lume.ufrgs.br/handle/10183/ 36312

8 Ministério da Saúde (BR). Secretaria da Gestão do Trabalho e da Educação em Saúde. Curso de formação de facilitadores em educação permanente em saúde: unidade de aprendizagem análise do contexto da gestão e das práticas de saúde [Internet]. Rio de Janeiro: FIOCRUZ, 2005[acesso em 2019 abr 19]. Disponível em: http://bvsms.saude.gov.br/bvs/public acoes/curso_facilitadores_unidade_pr atica.pdf

9 Scafuto JCB, Benedetto S, Delgado PGG. Formação e educação permanente em saúde na perspectiva da desinstitucionalização. Comun. ciênc. saúde. [Internet]. 2017[acesso em 2019 mar 18];28(3/4):350-58. Disponível em: http://www.escs.edu.br/revistaccs/in dex.php/comunicacaoemcienciasdasa ude/article/view/277/109

10 Delgado PGG. Reforma Psiquiátrica. In: Grigolo TM, Motetti-Pires RO, organizadores. Políticas de saúde mental e direitos humanos. Florianópolis: Universidade Federal de Santa Catarina [Internet]; 2014[acesso 
em 2019 maio 05]:11-28. Disponível em:

https://unasus.ufsc.br/alcooleoutrasd rogas/files/2015/03/Modulo-2.pdf

11 Azevedo DM, Oliveira AM de, Melo G de SM, Salvetti $M$ de $G$, Vasconcelos QLD de AQ, Torres G de V. Avaliação da assistência em saúde num centro de atenção psicossocial na perspectiva dos profissionais. Rev. bras. pesqui. saúde. [Internet]. 2014[acesso em 2019 abr 19];16(2):109-16. Disponível em:

http://periodicos.ufes.br/RBPS/articl e/view/9293/6467

12 Verona H. Pequeno ensaio sobre educação na saúde: o encontro com o usuário como acontecimento de aprendizagem ou aprendizagem baseada no encontro com o usuário. In: Conselho Regional de Psicologia de Minas Gerais (CRP/MG). Contribuições do Seminário Mineiro Psicologia na Saúde Pública. Belo Horizonte; 2015:33-7.

13 Meirelles MCP, Hypolito AM, Kantorski LP. Avaliação de quarta geração: reciclagem de dados. J. nurs. health. [Internet]. 2012[acesso em 2018 nov 22];2(1):63-74. Disponível em:

https://periodicos.ufpel.edu.br/ojs2/ index.php/enfermagem/article/viewF ile/3457/2842

14 Sampaio TJC, Guimarães JMX, Carneiro C, Garcia-Filho C. O trabalho em serviços de saúde mental no contexto da reforma psiquiátrica: um desafio técnico, político e ético. Ciênc. Saúde Colet. [Internet]. 2011[acesso em 2018 nov 17];16(12):4685-94. Disponível http://www.scielo.br/pdf/csc/v16n12 /17.pdf

15 Pitano SC. A educação problematizadora de Paulo Freire, uma pedagogia do sujeito social. Inter ação [Internet]. 2017[acesso em 2019 abr 15]42(1):87-104. Disponível em: https://revistas.ufg.br/interacao/arti cle/download/43774/23208/

16 Davini MC. La formación em la prática docente. $1^{\text {a }}$ ed. Buenos Aires: Paidós; 2015.

17 Kantorski LP, Jardim V da R, Wetzel C, Olschowsky A, Schneider JF, Heck $\mathrm{RM}$ et al. User satisfaction with psychosocial healthcare services, Southern Brazil. Rev. saúde pública (Online). [Internet]. 2009[cited 2018 Nov. 22];43 Suppl1:1-6. Available from:

http://www.scielo.br/pdf/rsp/v43s1/ en_748.pdf

18 Farias ID, Thofehrn MB, Porto AR, Kantorski LP. Oficinas terapêuticas: percepção de trabalhadores dos Centros de Atenção Psicossocial. J. nurs. health. [Internet]. 2017[acesso em 2018 nov 22];7(3):e177307. Disponível em: https://periodicos.ufpel.edu.br/ojs2/ index.php/enfermagem/article/view/ $10109 / 8086$

19 Leite LS, Rocha KB. Educação permanente em saúde: como e em que espacos se realiza na perspectiva dos profissionais de saúde de Porto Alegre. Estud. psicol. (Natal). [Internet]. 2017[acesso em 2019 mar 19];22(2):203-13. Disponível em: http://pepsic.bvsalud.org/scielo.php? script=sci_arttext\&pid=S1413294X2017000200009 


\section{JOURNALOF \\ NURSING \\ ${ }^{\text {AND HEALTH }}$}

20 Silva GM, Ness 0, Guanaes-Lorenzi C. Continuing education in mental health: critical moments to analyse group process. Paidéia (Ribeirão Preto, Online). [Internet]. 2018[cited 2019 Mar. 19];28:e2834. Available from: http://scielo.br/pdf/paideia/v28/198 2-4327-paideia-28-e2834.pdf

21 Signor E, Silva LAA da, Gomes IEM, Ribeiro RV, Kessler M, Weiller TH et al. Educação permanente em saúde: desafios para a gestão em saúde pública. Rev. enferm. UFSM. [Internet]. 2015[acesso em 2018 nov 22];5(1):1-11. Disponível em: https://periodicos.ufsm.br/reufsm/ar ticle/view/14766/pdf2222

22 Puggina CC, Amestoy SC, Fernandes HN, Carvalho LA, Báo ACP, Alves FO. Educação permanente em saúde: instrumento de transformação do trabalho de enfermeiros. Espaç. saúde (Online). [Internet]. 2015[acesso 2018 nov 22];16(4):87-97. Disponível em: http://uel.

$\mathrm{br} / \mathrm{revistas} / \mathrm{uel} /$ index.php/espacopara saude/article/view/22580/11

Data de submissão: 15/05/2018

Data de aceite: 15/04/2019

Data de publicação: 08/05/2019 